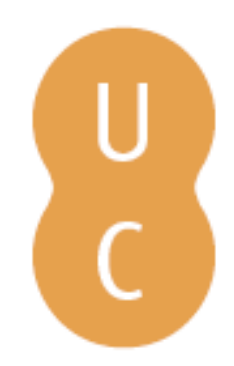

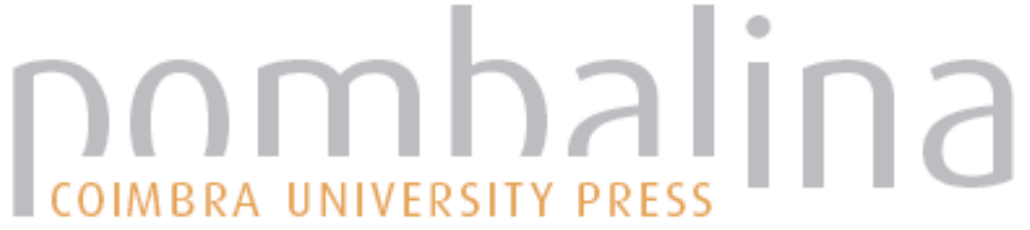

\section{O cruzamento de saberes na aula de inglês: contributos para uma prática multidisciplinar}

Autor(es): $\quad$ Luís, Ana R., ed. lit.

Publicado por: Imprensa da Universidade de Coimbra

URL

persistente: URI:http://hdl.handle.net/10316.2/35907

DOI: $\quad$ DOI:http://dx.doi.org/10.14195/978-989-26-0690-3

Accessed : $\quad$ 12-Mar-2017 12:25:35

A navegação consulta e descarregamento dos títulos inseridos nas Bibliotecas Digitais UC Digitalis, UC Pombalina e UC Impactum, pressupõem a aceitação plena e sem reservas dos Termos e Condições de Uso destas Bibliotecas Digitais, disponíveis em https://digitalis.uc.pt/pt-pt/termos.

Conforme exposto nos referidos Termos e Condições de Uso, o descarregamento de títulos de acesso restrito requer uma licença válida de autorização devendo o utilizador aceder ao(s) documento(s) a partir de um endereço de IP da instituição detentora da supramencionada licença.

Ao utilizador é apenas permitido o descarregamento para uso pessoal, pelo que o emprego do(s) título(s) descarregado(s) para outro fim, designadamente comercial, carece de autorização do respetivo autor ou editor da obra.

Na medida em que todas as obras da UC Digitalis se encontram protegidas pelo Código do Direito de Autor e Direitos Conexos e demais legislação aplicável, toda a cópia, parcial ou total, deste documento, nos casos em que é legalmente admitida, deverá conter ou fazer-se acompanhar por este aviso.

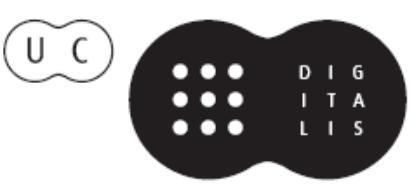




\section{O CRUZAMENTO DE SABERES NA AULA DE INGLÊS}

CONTRIBUTOS PARA UMA PRÁTICA MULTIDISCIPLINAR

ANA R. LUÍS COORD.

IMPRENSA DA UNIVERSIDADE DE COIMBRA COIMBRA UNIVERSITY PRESS 


\section{ÁRVORE, REDE E LABIRINTO: O HIPERTEXTO ELETRÓNICO NA APRENDIZAGEM E NO ENSINO}

Manuel Portela

\section{Introdução}

Ao longo das duas últimas décadas, a rápida expansão da textualidade eletrónica em rede fez do hipertexto eletrónico uma das ferramentas centrais no processo de ensino-aprendizagem. A mudança nas tecnologias de comunicação originou assimetrias evidentes entre as literacias grafocêntricas tradicionais, predominantes na geração dos docentes, e as literacias multimodais digitais, típicas na geração dos discentes. A reflexão teórica inicial, realizada quer pela teoria dos média, quer pelas ciências da educação, sobrevalorizou os efeitos cognitivos e pedagógicos das novas tecnologias. Com efeito, as mudanças efetivas nas práticas de ensino-aprendizagem decorrentes da introdução dos média digitais continuam a ser bastante limitadas. Por outro lado, o impacto das práticas da sociedade da informação em rede no desenvolvimento das capacidades cognitivas de crianças, adolescentes e jovens tem sido objeto de avaliações opostas.

O objetivo deste artigo é refletir sobre o potencial da Internet enquanto arquivo aberto de materiais e ferramentas suscetíveis de serem incorporados em processos formais de aprendizagem. O modelo de reflexão aqui proposto usa a própria Internet como espaço de reconcetualização da natureza da aprendizagem e do ensino, sem estabelecer modelos educativos a priori como critérios de avaliação do universo hipertextual. Propõe-se explorar formas de utilização do hipertexto eletrónico que possam torná-lo mais produtivo num contexto formal de aprendizagem e de ensino, pensando a Internet como meio e como modelo de apren- 
dizagem. Serão descritas algumas práticas e atividades que ensaiam uma compreensão mais profunda da lógica hipertextual e dos seus usos em processos cognitivos. Espera-se deste modo contribuir para uma mudança concetual no modo de encarar o hipertexto eletrónico e para uma maior integração dos recursos eletrónicos em rede no processo educativo.

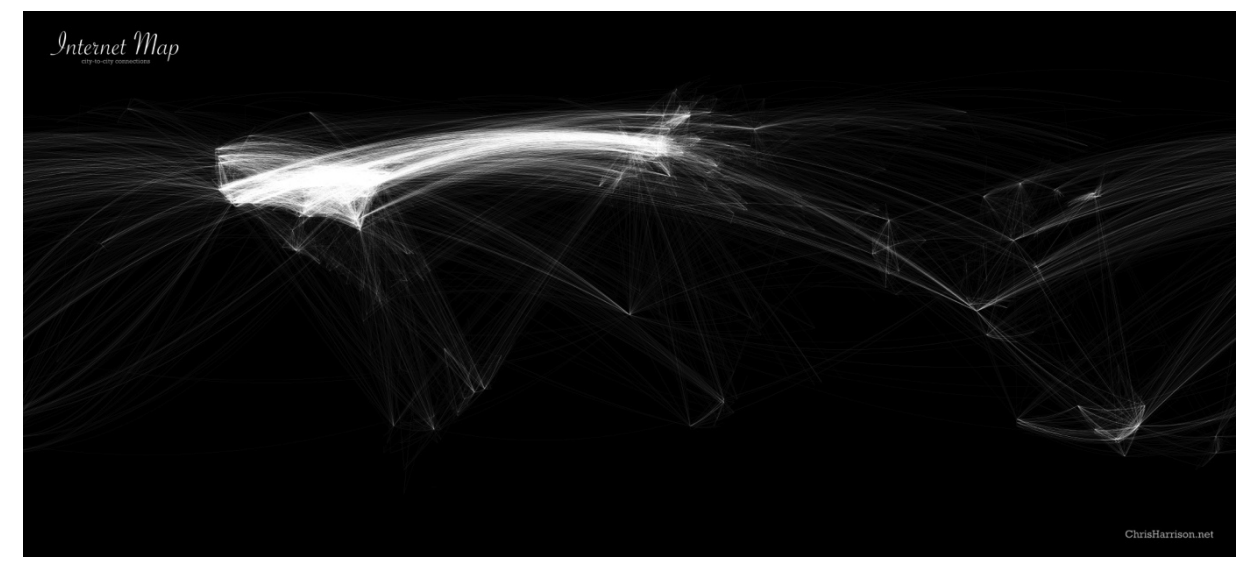

Figura 1. Internet Map: World City-to-City Connections. (c) 2007 Chris Harrison.

Este ensaio começa com uma breve reflexão sobre noções de ensino-aprendizagem na sua relação com as tecnologias informáticas de comunicação. Considera em seguida a natureza particular da literacia digital e do hipertexto eletrónico. Por fim, descreve de modo exemplificativo um conjunto de formas, práticas e regras que podem ajudar os docentes a tirar melhor partido do uso dos recursos eletrónicos em linha na sala de aula. São tratadas questões como 'ensinar e aprender com hipertexto', 'o hipertexto como texto coletivo em construção', 'como avaliar um sítio web?', 'a utilização de fontes eletrónicas' e 'o manual escolar no contexto da Internet'. Além de uma pequena bibliografia selecionada, são indicadas em anexo, a título de exemplo, algumas ferramentas e fontes em linha úteis nas aulas de Língua Inglesa. 


\section{Ensino, aprendizagem e tecnologias de informação}

One chief effect of electronic hypertext has been the way it challenges now-conventional assumptions about teachers, learners, and the institutions they inhabit. It changes the roles of teacher and student in much the same way it changes those of writer and reader. Its emphasis on the active, empowered reader, which fundamentally calls into question general assumptions about reading, writing, and texts, similarly calls into question our assumptions about literary education and its institutions that so depend on these texts. (Landow 2006:272)

As práticas formais de ensino estão, desde os seus primórdios, diretamente ligadas às tecnologias de comunicação. Da identificação entre ensino e letra resultou a produção das sociedades grafocêntricas que colocaram a escrita no centro dos seus processos de reprodução e de organização. A escola definiu-se desde a Antiguidade como a instituição da letra e da sua disciplina. A institucionalização e generalização do alfabeto (e de outras formas de escrita) acelerou-se com a invenção da imprensa, que permitiu transformar a leitura e a escrita da letra numa poderosa ferramenta cognitiva e de socialização dos indivíduos, e de administração e controle das sociedades. A literacia da letra impressa tornou-se de tal forma dominante nas práticas pedagógicas dos últimos séculos que pôde identificar-se quase inteiramente com a própria ideia de escola, de ensino e de aprendizagem. O advento dos meios eletrónicos digitais nas últimas décadas do século XX constitui uma reconfiguração desse currículo histórico centrado na escrita e na leitura da letra, atualmente designado como literacia digital.

Na nova situação comunicacional, dois aspetos em particular contribuem para redefinir a literacia: a capacidade de integração das materialidades da escrita, do som, da imagem e da imagem animada em modos de comunicação multimodal; e a possibilidade de integração em redes, síncronas e assíncronas, de todos os artefactos comunicativos produzidos através da integração daquelas materialidades específicas. Além disso, 
uma parte cada vez mais significativa do património documental anterior (bibliográfico, fonográfico, cinematográfico, etc.) é republicada sob formas digitais, juntando-se deste modo à produção entretanto nascida em meio digital. Por outro lado, a ubiquidade das tecnologias de informação e comunicação, nos múltiplos espaços públicos e privados, resulta num conjunto de interações entre as literacias grafocêntricas impressas e as literacias multimodais digitais. O crescimento exponencial de um espaço público eletrónico, mantido por milhões de servidores e de computadores pessoais ligados em rede, redefine a publicação e a distribuição da informação na era digital. Este espaço audiovisual eletrónico de escrita e leitura torna possível a coexistência contígua de inúmeros atos e artefactos de comunicação, em múltiplos graus de formalidade e informalidade, tanto de natureza institucional, como de caráter individual. ${ }^{1}$

A descrição e a análise dos efeitos das novas tecnologias sobre as práticas culturais e linguísticas originaram nas últimas duas décadas um largo corpo de estudos, que atravessa transversalmente muitas disciplinas das ciências sociais e humanas. Seja no campo das tecnologias educativas, através do desenvolvimento de software educativo, seja no campo da observação das mudanças nos comportamentos e relações sociais, este corpo de estudos reflete quer a perceção do valor pedagógico e didático das ferramentas digitais, quer a consciência do alcance vasto das mudanças tecno-sociais em curso. No primeiro caso, refira-se o desenvolvimento de plataformas especificamente orientadas para tirar partido das multimodalidades e das interações em rede, síncronas e assíncronas, nos processos de ensino-aprendizagem. É o que acontece com as novas práticas multimédia de ensino em linha, combinadas ou não com o ensino presencial (e-learning e b-learning). No segundo caso, constate-se o surgimento de revistas e projetos de investigação especificamente orientados para o estudo das dinâmicas entre tecnologias digitais e práticas sociais

\footnotetext{
${ }^{1}$ É o potencial deste universo descentrado e aparentemente caótico de materiais que pretendo tomar como objeto central deste artigo e não os sítios ou aplicações concebidos de raiz como projetos didáticos e educativos, embora estes sejam também considerados enquanto parte do universo de documentos em linha.
} 
e cognitivas. ${ }^{2}$ Isto mesmo é manifesto no desenvolvimento de uma sociologia da cultura digital e na emergência de projetos de investigação e de empresas baseadas na criação de programas informáticos que analisam de forma agregada os múltiplos padrões da cultura digital. ${ }^{3}$

Estas mudanças tecnoculturais são resultado da transformação geral dos processos produtivos na sociedade da informação, reforçadas por políticas de financiamento e incentivo ao uso dos meios digitais em todos os setores. Na última década, várias iniciativas quer da União Europeia, quer dos governos nacionais melhoraram significativamente as infraestruturas de informação e comunicação nos diferentes níveis de ensino. Entre as principais iniciativas em Portugal refiram-se o 'Programa Operacional da Sociedade do Conhecimento' [www.posc.mctes.pt/index.

${ }^{2}$ Uma série recente de quatro livros, resultantes de um projeto de investigação em curso no Massachusetts Institute of Technology sobre as tecnologias e o sujeito, trata aquela questão, combinando perspetivas psicológicas, sociológicas e antropológicas. Cf. Sherry Turkle, ed., Evocative Objects: Things We Think With, MIT Press, 2007; Sherry Turkle, ed., Falling for Science: Objects in Mind, MIT Press, 2008; Sherry Turkle, ed., The Inner History of Devices, MIT Press, 2008; e Sherry Turkle, ed., Simulation and Its Discontents, MIT Press, 2009. Sherry Turkle tem sido a diretora da MIT Initiative on Technology and Self (http:// web.mit.edu/sturkle/www/techself), iniciada em 2001. Vejam-se também Sherry Turkle, The Second Self: Computers and the Human Spirit, Cambridge, Mass: MIT Press, 2004 [1 ${ }^{\mathrm{a}}$ ed. 1984] e Life on the Screen: Identity in the Age of the Internet, Cambridge, Mass: MIT Press, 1995, ambos com edição portuguesa (cf. bibliografia final). David Crystal sintetizou em Language and the Internet, Cambridge University Press, 2006 [1 $1^{\mathrm{a}}$ ed. 2001], diversos efeitos da comunicação eletrónica sobre os usos da língua e descreveu a emergência de uma linguística aplicada à Internet.

${ }^{3}$ First Monday (fundada em 1996; publicada pela Universidade de Illinois em Chicago, http://firstmonday.org/htbin/cgiwrap/bin/ojs/index.php/fm/index), Journal of ComputerMediated Communication (fundada em 1995; publicada pela Faculdade de Biblioteconomia \& Ciências da Informação da Universidade de Indiana, http://jcmc.indiana.edu/, 1995-2007, http://www3.interscience.wiley.com/journal/117979306/home, 2007-2010) e Language@ Internet (fundada em 2004; publicada pelo Digital Peer Publishing, North Rhine-Westphalia, e pelo Centro das Bibliotecas Universitárias em Colónia, http://www.languageatinternet.de/) são três exemplos de revistas académicas em linha que abordam a comunicação mediada por computador a partir de perspetivas culturais, sociológicas e linguísticas. Na última década, diversos projetos têm analisado a especificidade das literacias digitais. Veja-se, por exemplo, Transliteracies: Research in the Technological, Social, and Cultural Practices of Online Reading (iniciado em 2005, na Universidade da Califórnia em Santa Bárbara, http:// transliteracies.english.ucsb.edu/category/research-project). No que diz respeito a investigação aplicada à Internet, sublinhem-se os projetos que desenvolvem aplicações e ferramentas para edição e colaboração em linha e também os inúmeros projetos, proprietários e em código aberto, dedicados à visualização de dados. Vejam-se os projetos compilados por Manuel de Lima, desde 2008, no sítio web Visual Complexity, http://www.visualcomplexity. com/vc/ (consultado a 26 Ago 2010). 
php (2000-2006)], o 'Programa e-U, Campus Virtual' [http://www.e-u.pt/ (2003-presente)] e o 'Plano Tecnológico Nacional' [http://www.planotecnologico.pt/ (2005-presente)]. Com um ritmo mais ou menos intenso, a generalização das tecnologias educativas digitais tem sido um objeto continuado das políticas públicas nacionais. O Ministério da Educação dos Estados Unidos da América, por exemplo, lançou recentemente um novo Plano Educativo Tecnológico [http://www.ed.gov/technology/netp2010 (2010)], com o objetivo de aumentar a ubiquidade dos processos digitais nas práticas escolares.

Apesar da perceção generalizada desta alteração e da sua evidência quotidiana nas nossas vidas e nas dos nossos alunos, nem sempre conseguimos tirar o melhor partido do potencial educativo e didático dos novos média e da Internet. Por um lado, o discurso ideológico dominante sobrevaloriza de forma acrítica as novas tecnologias como se o dispositivo tecnológico por si só gerasse melhores práticas de aprendizagem e de ensino. A introdução de novas ferramentas educativas informáticas - de que a instalação dos quadros interativos nas escolas portuguesas constitui um dos exemplos mais recentes - vem muitas vezes toldada por um discurso tecnofílico, cheio de chavões publicitários, que prejudica a compreensão da natureza específica da tecnologia, isto é, das suas potencialidades e das suas limitações, e dificulta a sua integração plena nas práticas educativas disciplinares. Um desejo irracional de automatização das tarefas, uma conceção neo-behaviorista da aprendizagem e uma valorização excessiva dos dispositivos de visualização - em detrimento dos modos manuais, corporais e verbais de interação com o mundo e com os outros - refletem, muitas vezes, uma interiorização acrítica da cultura digital no que esta contém de dispositivo tecnológico e ideológico de controlo e de disciplina social. A aceleração do tempo criada pela instantaneidade das representações automáticas tem, assim, o efeito perverso de colocar o aprendente como espetador e não como construtor do seu próprio conhecimento, e de submeter o docente aos constrangimentos dos dispositivos.

Por outro lado, os docentes têm dificuldade em imaginar como usar os novos recursos para mudar hábitos e disposições cristalizados nas suas 
práticas pedagógicas. Os modos de utilização lúdica e social dos meios digitais, comuns para uma parte cada vez mais significativa de crianças, adolescentes e jovens do mundo pós-industrializado, não se transpõem automaticamente para o uso modular e formalizado necessário a uma aprendizagem gradual de processos e conceitos complexos em sala de aula. Ao mesmo tempo, parece evidente que a organização associativa da informação que o hipertexto eletrónico e outras ferramentas informáticas materializaram nos últimos vinte anos constitui uma poderosa base de construção e partilha descentralizada de conhecimento. A este processo de agregação da informação escrita e gráfica eletrónica soma-se a natureza crescentemente multimodal da informação produzida, com um aumento exponencial de ficheiros de som e de vídeo. De resto, é provável que os recursos educativos e didáticos (manuais escolares e outros materiais complementares, instrumentos de avaliação, modelos experimentais, etc.) sejam predominantemente eletrónicos e em linha dentro de poucos anos. O momento atual é pois um momento de acelerada transição para um ambiente educativo eletrónico em grande parte das disciplinas, nas quais se generalizará a interação individual com um corpus cada vez maior de ficheiros verbais, gráficos e audiovisuais e nos quais se acentuará também a interação entre discentes e docentes mediada por computador.

Um conjunto vasto de tópicos tem sido objeto de investigação aplicada nas últimas duas décadas. A criação de plataformas digitais que funcionam como extensão do espaço de trabalho e interação da sala de aula é um dos campos de intensa colaboração entre programadores informáticos e educadores. Existem atualmente em todo o mundo inúmeras plataformas com aqueles objetivos em todos os níveis de ensino. Uma das plataformas mais usadas no ensino secundário e superior em Portugal, por exemplo, é a plataforma de gestão de conteúdos escolares Moodle (http://moodle.org/), desenvolvida em regime de código aberto. Escolas e universidades, de forma mais ou menos programática, instalam e promovem a utilização desta e de outras plataformas educativas ou ambientes de aprendizagem virtual. Refiram-se, a título de exemplo, os ambientes virtuais de colaboração e aprendizagem Sakai (http://sakaiproject.org/), Blackboard (http://www.blackboard.com/), TopClass (www.wbtsystems. 
com), E-College (http://www.ecollege.com/index.learn), RightPath (http:// www.rightreasontech.com/student-success-system/RightPath.aspx) e It's learning (http://www.itslearning.net/). Estas aplicações incorporam na sua estrutura informática um determinado modelo das formas, práticas e instituições educativas. Enquanto ambiente virtual de aprendizagem, podem funcionar como substituto ou como extensão do ambiente presencial. Nestas plataformas, a didatização modular dos conteúdos, caraterística do manual escolar, pode combinar-se com a comunicação (síncrona e assíncrona), com o repositório de textos e imagens e com a utilização de vídeos educativos multimédia.

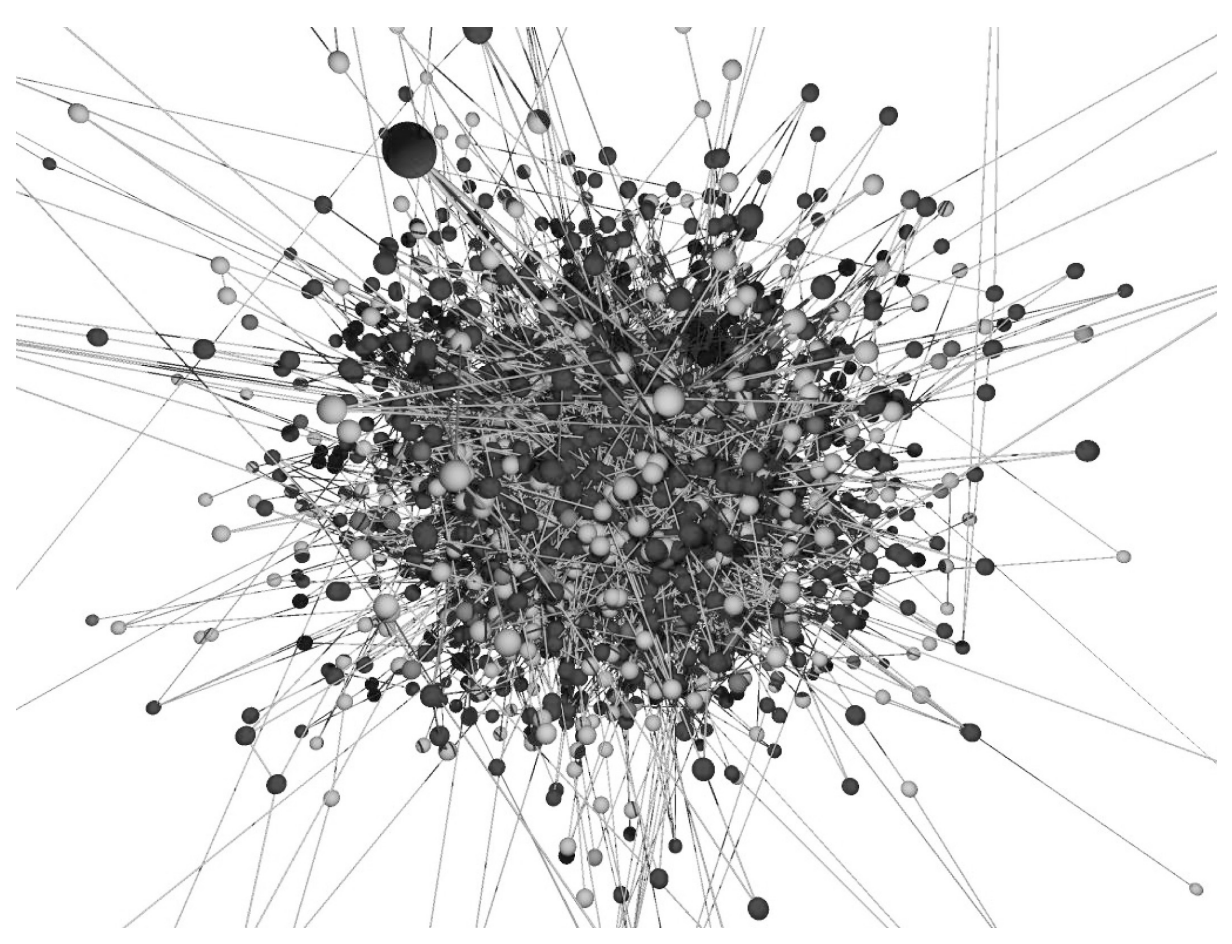

Figura 2. IP Mapping. (C) 2001 Stephen Coast.

Em suma, a tentativa de adaptar ou construir ferramentas informáticas úteis no processo formal de ensino-aprendizagem é visível nas plataformas em linha, com maior ou menor componente de ensino à distância, 
na criação de portais temáticos de natureza educativa e em projetos de edição e publicação que envolvem docentes e discentes. A crescente dimensão social das ferramentas da chamada Web 2.0, que se tornaram dominantes durante a última década, aumentou o dinamismo de comunicação e de publicação em linha, incrementando a produção colaborativa e a participação coletiva no espaço público eletrónico. Algumas destas ferramentas, como os wikis e os blogues, têm sido usados também em experiências formais de ensino-aprendizagem. Aquilo que me proponho fazer nas duas secções seguintes, refletindo a partir da observação das mudanças em curso e da minha experiência como educador, é sugerir algumas práticas que permitem tirar melhor partido dos recursos em linha existentes. A atenção centrar-se-á portanto na utilização da própria Internet como um recurso valioso. Embora a maior parte dos exemplos indicados no anexo final diga respeito ao ensino das línguas e de áreas afins, os mesmos princípios, critérios e práticas são válidos, com as devidas adaptações, para outras disciplinas.

\section{Hipertexto eletrónico: árvore, rede e labirinto}

The hypertext link is the most fundamental structural property of the Web, without which the medium would not exist. It has parallels in some of the conventions of traditional written text - especially in the use of the footnote number or the bibliographical citation, which enables a reader to move from one place in a text to another - but these are optional features, and nothing in traditional written language remotely resembles the dynamic flexibility of the Web. (Crystal 2006:210)

Na definição original de hipertexto, formulada em 1965, Theodor Holm Nelson sublinhou o seu potencial cognitivo e metacognitivo. Este potencial resulta da interação individual com um corpus vasto de materiais multimédia através de processos associativos e coletivos abertos. A literatura transforma-se num corpo de documentos multimodais interligados que 
os utilizadores percorrem, anotam e modificam através de interações singulares, resultantes do próprio processo de produção de conhecimento:

Let me introduce the word "hypertext" to mean a body of written or pictorial material interconnected in such a complex way that it could not conveniently be presented or represented on paper. It may contain summaries, or maps of its contents and their interrelations; it may contain annotations, additions and footnotes from scholars who have examined it. Let me suggest that such an object and system, properly designed and administered, could have great potential for education, increasing the student's range of choices, his sense of freedom, his motivation, and his intellectual grasp. (Nelson:144)

As estruturas hipertextuais podem ser concebidas de modo a maximizar a modularização da informação e os percursos associativos entre módulos, mas é a fragmentação e reassociação de materiais inerentes ao modo de leitura hipertextual que potencia a sua produtividade informativa e expressiva. A flexibilidade cognitiva que Ted Nelson reconheceu no hipertexto enquanto instrumento de produção de conhecimento e de associação da informação aproxima-se das teorias construtivistas da aprendizagem.

Timothy Berners-Lee - inventor do protocolo World Wide Web, diretor do Word Wide Web Consortium (W3C; http://www.w3.org/) e um dos proponentes da Web semântica - e outros investigadores têm sublinhado a natureza emergente e imprevisível das interações entre infraestruturas, aplicações informáticas e relações sociais mediadas pelos dispositivos digitais e pelo software. A Internet é justamente o resultado dessa retroalimentação continuada que integra práticas sociais, dispositivos eletrónicos e algoritmos num mesmo sistema:

At the micro scale, the Web is an infrastructure of artificial languages and protocols; it is a piece of engineering. However, it is the interaction of human beings creating, linking, and consuming information that generates the Web's behavior as emergent properties at the macro scale. These properties often generate surprising properties that require new analytic methods to be 
understood. Some are desirable and therefore to be engineered in; others are undesirable and if possible engineered out. We also need to keep in mind that the Web is part of a wider system of human interaction; it has profoundly affected society, with each emerging wave creating new challenges and opportunities in making information more available to wider sectors of the population than ever before. (Hendler et al. 2008:63)

A Web gera dinâmicas e fenómenos emergentes também no que diz respeito aos modelos de aprendizagem. A aprendizagem formal pode ser descrita como um percurso concetual concebido para interferir na dinâmica das representações do real de que o sujeito dispõe e desenvolver assim novas capacidades de interação com o mundo e com os outros. Podemos identificar pelo menos quatro tipos de interferência na dinâmica das representações: (a) acrescentar às representações anteriores; (b) modificar as representações anteriores; (c) substituir as representações anteriores; (d) complexificar as representações anteriores. A aprendizagem formal favorece igualmente uma tomada de consciência do conhecimento enquanto processo de construção, dependente de um ponto de vista e de uma perspetiva. Esta tomada de consciência da natureza processual e construída do conhecimento manifesta-se através de: (a) atos de recontextualização, isto é, de aplicação de conceitos em novos contextos; (b) atos de apropriação, isto é, de integração de novos conhecimentos no conjunto de representações anteriores; (c) atos de metacognição, isto é, de autorrepresentação sobre o modo como o sujeito constrói o seu próprio conhecimento, e de que forma determinada perspetiva se reflete no objeto construído.

Considerado como conjunto de percursos possíveis entre documentos ou segmentos de documentos, o hipertexto eletrónico materializa fundamentalmente três tipos de estrutura: a árvore, a rede e o labirinto. As estruturas arborescentes correspondem a estruturas hierárquicas determinadas pela sintaxe informática que estabelece as relações entre ficheiros em níveis sucessivos de encaixe e dependência. As ligações principais que, dentro de cada sítio, abrem uma nova página organizam-se hierarquicamente. Por seu turno, as estruturas reticulares resultam das ligações 
transversais entre ficheiros independentemente do nível hierárquico que cada ficheiro ocupa no sítio de publicação original. As ligações entre sítios, por exemplo, criam novos nós que expandem reticularmente a estrutura associativa. O mesmo acontece com os resultados de uma pesquisa aberta que coloca em contiguidade documentos provenientes de conjuntos documentais disjuntos e concetualmente afastados. Finalmente, as teias labirínticas resultam da interação constante entre os dois tipos de estruturas anteriores. Ao percorrer um sítio web específico ou o conjunto da World Wide Web enquanto agregado de páginas e de sítios, os leitores fazem percursos labirínticos, abrindo ligações para novas páginas ou regressando a páginas já percorridas.

Podemos ainda pensar no hipertexto eletrónico não só como o agregado multimodal de materiais e das suas ligações, mas também enquanto modo de escrita, publicação e leitura, isto é, como o conjunto de práticas tecno-sociais que institui e promove a atual literacia digital. A flexibilidade do hipertexto eletrónico, particularmente nos programas e plataformas caraterísticos da Web 2.0, resulta numa crescente socialização das práticas de escrita, publicação e leitura. Enquanto espaço aberto de escrita, publicação e leitura, permite aos escrileitores acrescentar novos materiais e novas ligações, que ficam disponíveis para novos atos de leitura e de escrita. As redes de escrita e leitura caraterísticas da cultura impressa tendem a reconfigurar-se em função das capacidades tecnológicas do novo meio, que coloca em contiguidade virtual todos os materiais e todos os utilizadores, independentemente da sua localização institucional e geográfica. A possibilidade de ligação remota, combinada com a crescente mobilidade dos dispositivos, promove a ubiquidade social e geográfica das interações mediadas por meios digitais.

Enquanto construção explícita de associações, o hipertexto pode ser usado como uma metáfora dos processos cognitivos de construção de conhecimento através da aprendizagem formal. Aos textos e ligações pré-definidos pelo hiperescritor somam-se os novos textos e ligações acrescentados pelo hiperleitor e ainda as ligações imprevisíveis geradas pelos algoritmos de pesquisa. O conjunto das associações nunca está inteiramente determinado: às ligações pré-existentes, isto é, as ligações 
ativas nos documentos consultados, acrescentam-se as ligações geradas pelos motores de pesquisa automática, que dependem dos termos de pesquisa introduzidos e dos algoritmos que realizam a pesquisa e hierarquizam os resultados. Deste processo, interativo e dinâmico, resulta a seleção e recombinação dos segmentos documentais segundo ligações geradas em resposta à intermediação conjunta de utilizadores e máquinas computacionais. Utilizador e máquina constituem-se como partes de um sistema cognitivo, um processo que N. Katherine Hayles descreve através dos conceitos de 'intermediação' (2008) e de 'leitura maquínica' (2010). As ligações explícitas constituem uma espécie de nível meta-informativo que oferece ao utilizador a meta-estrutura da informação apresentada. Mas as ligações explicitadas pelos códigos html são apenas um dos aspetos do processo de construção de associações que metaforiza na web o processo de aprendizagem. A lógica associativa parece ser intrínseca ao modo de funcionamento cerebral e ao processo de semiose em geral, pelo que a cultura algorítmica acentua a natureza emergente do sentido ao induzir processos combinatórios automáticos imprevistos.

A organização hipertextual da informação caraterizou desde sempre o modo de produção de materiais destinados ao ensino. Géneros hipertextuais como enciclopédias, dicionários, manuais, coletâneas e comentários dominaram os géneros didáticos desde a Antiguidade. Isto significa que a modularização da informação em níveis crescentes de complexidade e os dispositivos de referência cruzada entre fontes estiveram no centro dos métodos de ensino, das práticas didáticas e dos processos de arquivo e recuperação da informação. O desenvolvimento do hipertexto eletrónico apenas permitiu exponenciar os processos associativos internos e externos desenvolvidos pela cultura do códice manuscrito e do códice impresso, tornando possível cruzar os discursos para além das fronteiras disciplinares estabelecidas e mantidas pelas instituições do livro, como as bibliotecas e as universidades. Os factos atuais com maiores consequências parecem ser (1) o acesso ilimitado a uma variedade enorme de fontes digitais, e (2) a ausência da mediação do educador institucional nesse acesso. A escola, a biblioteca e o arquivo, enquanto instituições reguladoras do acesso ao conhecimento e à informação, perderam parte 
da sua exclusividade no papel de guardiãs, transmissoras e certificadoras da informação. Ao mesmo tempo, o hipertexto eletrónico e a Internet são trazidos para dentro da sala de aula com o objetivo de incrementar o acesso à informação e desenvolver novas práticas tecno-educativas.

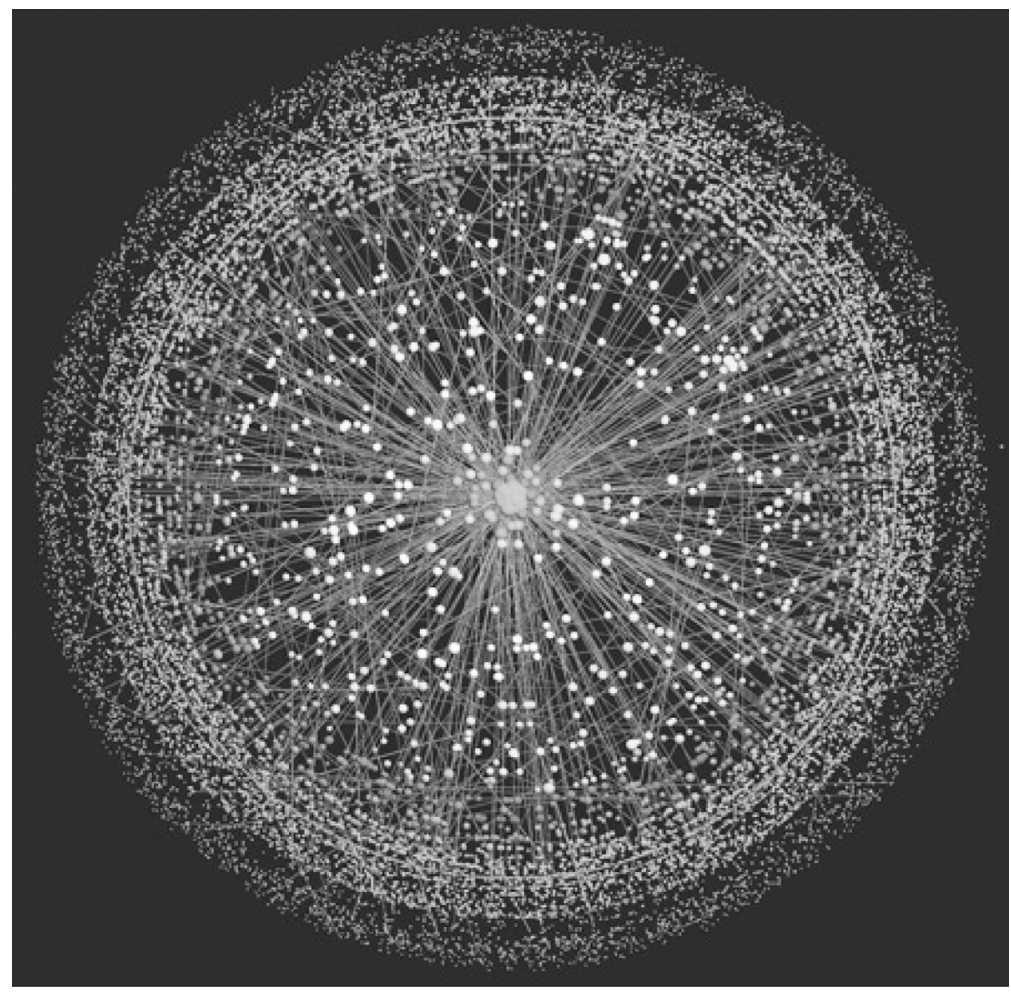

Figura 3. The shape of the online universe. () 2007 Shai Carmi et al.

Nas duas últimas décadas, encontramos sobretudo três tipos de experiência hipertextual eletrónica em contexto de aprendizagem. Nos anos 90 - antes de a publicação em linha se tornar na forma predominante de distribuição de conteúdos -, o hipertexto didático em CD-ROM constituiu uma das formas caraterísticas. Oferecidos como complementos multimédia aos manuais escolares ou sob a forma de dicionários e enciclopédias, estes projetos seguem em geral o modelo impresso, tirando partido das capacidades de armazenamento de informação e dos modos de visualização, 
apresentação, indexação e pesquisa específicos do meio digital. Muitos destes hipertextos didáticos e de referência transferiram-se entretanto para o espaço eletrónico em linha. Um segundo tipo de experiência engloba o hipertexto como projeto escolar, desenvolvido através da colaboração entre docentes e discentes - podendo tomar a forma de um sítio web, de um wiki ou de um blogue, por exemplo. Esta experiência tornou-se comum na última década, sobretudo depois da popularização das ferramentas dinâmicas de publicação através da interface dos browsers. No terceiro tipo de experiência refira-se o uso das formas hipertextuais tal como são geradas pelos atos de pesquisa automática e pela leitura por hiperligação. Trata-se, neste caso, de considerar a própria informação eletrónica em linha como um hipertexto de hipertextos, e de pensar a Internet como um recurso mobilizável de forma criativa para os processos de ensino e aprendizagem.

\section{A Internet como modelo de aprendizagem}

We argue that the single most important characteristic of the Internet is its capacity to allow for a worldwide community and its endlessly myriad subsets to exchange ideas, to learn from one another in a way not previously available. We contend that the future of learning institutions demands a deep, epistemological appreciation of the profundity of what the Internet offers humanity as a model of a learning institution. (Davidson e Goldberg:1-2)

Vários projetos de investigação recentes têm chamado a atenção para a Internet como um novo modelo de instituição de aprendizagem, de ensino e de investigação. Alguns autores vêem mesmo na Internet a possibilidade de uma mudança epistemológica e pedagógica, isto é, de uma mudança dos modelos e práticas de produção de conhecimento e de ensino. Tem aumentado a perceção de que a socialização inerente às ferramentas digitais e a automação algorítmica dos processos de compilação, 
estruturação e análise de dados alteram as práticas de investigação nas Humanidades (por exemplo McGann et al. 2010; Manovich 2010). Vários estudos desenvolvidos no campo das ciências da educação têm equacionado igualmente o potencial de mudança nas instituições e práticas de ensino, a todos os níveis de escolaridade. ${ }^{4}$ Cathy N. Davidson e David Theo Goldberg $(2009,2010)$ sublinham a socialização do conhecimento e os novos modos colaborativos e reticulares de aprendizagem digital como os principais potenciadores de uma alteração. Nesta perspetiva, não se trata tanto de adaptar a Internet à aula, mas sim do processo inverso. Trata-se de perceber de que modo é possível modificar o ensino e a aprendizagem a partir do conjunto de conteúdos e práticas gerados pela Internet, tomando a própria Internet como modelo de um novo paradigma de aprendizagem e de pensamento. Os espaços e interações digitais permitiriam imaginar uma reconfiguração significativa da situação pedagógica, nos seus métodos e práticas, que resultaria em novas modalidades de participação e de comunicação e em novas práticas de produção e de autorização do conhecimento.

Partindo da análise das práticas web, Davidson e Goldberg (2009:2625) sintetizam dez princípios para repensar o futuro das instituições de

${ }^{4}$ Vários relatórios recentes ('Reports on Digital Media and Learning'), resultantes de estudos financiados pela Fundação MacArthur, descrevem o potencial educativo dos média sociais, dos jogos de vídeo e de outros meios digitais, partindo da análise dos seus usos pelas crianças, adolescentes e jovens. Cf. Mizuko Ito, Heather Horst, Matteo Bittanti, danah boyd, Becky Herr-Stephenson, Patricia G. Lange, C. J. Pascoe, and Laura Robinson with Sonja Baumer, Rachel Cody, Dilan Mahendran, Katynka Z. Martínez, Dan Perkel, Christo Sims, and Lisa Tripp, Living and Learning with New Media: Summary of Findings from the Digital Youth Project, disponível em http://mitpress.mit.edu/books/full_pdfs/Living_and_Learning. pdf (consultado a 26 Ago 2010); Carrie James with Katie Davis, Andrea Flores, John M. Francis, Lindsay Pettingill, Margaret Rundle, and Howard Gardner, Young People, Ethics, and the New Digital Media: A Synthesis from the Good Play Project, Cambridge, Mass: The MIT Press, 2009, disponível em http://mitpress.mit.edu/books/full_pdfs/Young_People_Ethics_and_New_Digital_Media.pdf (consultado a 26 Ago 2010); Henry Jenkins, with Ravi Purushotma, Margaret Weigel, Katie Clinton, and Alice J. Robison Confronting the Challenges of Participatory Culture: Media Education for the 21st Century, Cambridge, Mass: The MIT Press, 2009, disponível em http://mitpress.mit.edu/books/full_pdfs/Confronting_the_Challenges.pdf (consultado a 26 Ago 2010); Joseph Kahne, Ellen Middaugh, and Chris Evans, The Civic Potential of Video Games, Cambridge, Mass: The MIT Press, 2009, disponível em http://mitpress.mit.edu/books/full_pdfs/Civic_Potential_of_Games.pdf (consultado a 26 Ago 2010). Veja-se ainda o sítio web dedicado a este conjunto de projetos: 'Building the Field of Digital Media and Learning' http://digitallearning.macfound.org/site/c.enJLKQNlFiG/ b.2029199/k.94AC/Latest_News.htm (consultado a 26 Ago 2010). 
ensino: (1) autoaprendizagem, resultante dos modos relacionais de leitura hipertextual em rede; (2) estruturas horizontais de aprendizagem, que curto-circuitam os modos hierárquicos e verticais típicos das instituições de ensino e colocam ênfase na aprendizagem colaborativa dos processos; (3) passagem da autoridade presumida à credibilidade coletiva, com o desenvolvimento de práticas interdisciplinares e da partilha de perspetivas; (4) pedagogia descentrada, isto é, dependente de modos descentrados e abertos de produção e recolha de informação; (5) aprendizagem em rede, com uma presença cada vez mais significativa de formas colaborativas e cooperativas de produção de conhecimento; (6) ensino aberto, isto é, baseado na produção livre de cultura e de conhecimento e em trocas intelectuais abertas, opondo-se às formas proprietárias, exclusivas e restritivas; (7) aprendizagem como interatividade e conectividade, isto é, dependente das trocas comunicativas inerentes à arquitetura social das redes eletrónicas; (8) aprendizagem ao longo da vida, não só em consequência das rápidas mudanças nos processos produtivos económicos mas também como parte intrínseca da sociabilidade da cultura digital; (9) as instituições de ensino como redes de mobilização, que incorporam num modo de funcionamento mais flexível a cultura em rede que carateriza o mundo digital; (10) escalabilidade flexível e simulação, ou seja, a presença de múltiplas escalas nos processos de produção de conhecimento, dos pequenos grupos locais às grandes instituições internacionais, e o uso da simulação virtual como metodologia generalizada de estudo de processos sociais e naturais.

A minha experiência com a Internet na sala de aula e com a sala de aula na Internet, nos últimos dez anos, comprova este potencial de transformação digital das práticas letivas. A criação de blogues de aula coletivos, que funcionam como espaço de reflexão e descoberta contínua sobre a criação e a mediação digital, e cuja produção se transformou também no conteúdo das próprias aulas, é um exemplo do tipo de presença da Internet na aula e da aula na Internet que resulta em circuitos de aprendizagem e de partilha ancorados na capacitação oferecida pela própria tecnologia e nas práticas expressivas que ela oferece. Nestes casos, a Internet e a cultura digital foram usadas simultaneamente como objeto de estudo e 
como meio de comunicação, retroalimentando a prática pedagógica com os conteúdos produzidos e selecionados coletivamente pelos utilizadores. Parte dos conteúdos curriculares foi produzida pelos discentes com recurso às funções de arquivo, pesquisa, edição e colaboração do próprio meio. ${ }^{5}$ Um segundo tipo de utilização, mais centrada na intervenção do docente, consiste na criação de um sítio web que compila de forma estruturada um conjunto de recursos de aprendizagem que são usados quer no decurso das atividades letivas na sala de aula, quer como informação complementar que os aprendentes podem explorar como extensão dos conteúdos curriculares no desenvolvimento de trabalhos individuais. ${ }^{6}$

Outra das atividades que merece mais atenção é a pesquisa eletrónica. A multiplicidade e diversidade de fontes disponíveis e a quantidade de informação gerada por qualquer ato de pesquisa automática exigem operações de seleção e triagem. A pesquisa automática tem a vantagem de nos revelar fontes relevantes que desconhecíamos, mas obriga a complexas operações de avaliação da qualidade das fontes e da adequação dos materiais encontrados a atividades e objetivos específicos. Por esse motivo, é em geral desaconselhável, para conteúdos de aprendizagem específicos, a pesquisa inteiramente aberta no universo da World Wide Web. Este modo de pesquisa tende a equalizar os diferentes tipos de fontes e leva os discentes a ignorarem o contexto de origem de determinada página web, como se não houvesse diferença entre um dicionário de história feito por especialistas e uma página de um trabalho escolar, ou como se as páginas da Wikipédia fossem adequadas para todo e qualquer assunto. Uma parte significativa do trabalho docente com o meio eletrónico na sala de aula consiste, por isso, no levantamento e na seleção de fontes adequadas aos conhecimentos e ao nível etário dos alunos. Uma boa utilização dos recursos implica geralmente uma seleção e avaliação prévia feita pelo docente dos

\footnotetext{
5 Vejam-se, em linha, os blogues DigLitMedia e DigArtMedia, produzidos respetivamente nas disciplinas de 'Literatura e Média na Era Digital' [http://www.diglitmedia.blogspot.com/; 2005-2006, 2006-2007 e 2008-2009] e de 'Introdução aos Novos Média' [http://digartmedia. wordpress.com/; 2008-2009 e 2009-2010].

6 Veja-se, em linha, o sítio DigLitWeb: Digital Literature Web [http://www.ci.uc.pt/diglit/; atualizado entre 2005 e 2013], que funciona simultaneamente como recurso pedagógico e como recurso de investigação para várias disciplinas de graduação e pós-graduação.
} 
sítios web adequados aos vários temas do programa da disciplina. Implica também que o docente compreenda os princípios básicos dos principais motores de pesquisa e das suas potencialidades e limitações.

Esta seleção de sítios web deve ser indicada, se necessário com orientações, como o universo de pesquisa a considerar pelos alunos. Este levantamento prévio tem a vantagem de permitir ao próprio docente descobrir modos de exploração dos materiais que não se limitem ao seu conteúdo informativo e contribui para uma utilização mais profícua dos recursos em linha, que, em geral, continuam a ser subutilizados em contexto de aprendizagem formal. Na pragmática da leitura em linha, o uso dos motores de pesquisa automática valoriza a procura apressada e meramente utilitária de informação em detrimento da exploração dos recursos associativos e modulares do hipertexto eletrónico tal como se encontram concebidos e estruturados em muitos sítios web. O tratamento agregado de todas as páginas e de ficheiros de um determinado formato feito pelos motores de pesquisa da Internet deve ser combinado com a exploração sistemática de projetos singulares, cujos recursos oferecem um percurso de aprendizagem estruturado baseado em fontes cuja qualidade científica e pedagógica pode ser pré-avaliada. O guião básico de perguntas que indico a seguir permite fazer uma avaliação sumária de sítios web suscetíveis de serem explorados posteriormente em processos formais de aprendizagem.

10 perguntas básicas sobre como avaliar um sítio web:

(1). O que contém o sítio?

(2). Quem são os autores/as do sítio web?

(3). Que instituições o albergam?

(4). Que destinatário explícito ou implícito tem?

(5). Como está organizado?

(6). Que ferramentas e funcionalidades oferece ao/à utilizador/a?

(7). As ligações internas e externas mantêm-se ativas?

(8). Quando foi criado?

(9). O sítio continua a ser atualizado?

(10). Como posso usá-lo enquanto aluno/a ou professor/a? 
Para além daquelas perguntas básicas de contextualização, uma avaliação da qualidade hipertextual do sítio pressupõe uma análise da sua estrutura e da sua forma hipermédia, tendo em conta critérios como coerência concetual, economia do design gráfico, facilidade de orientação e exploração do potencial do software e do ambiente virtual utilizado, entre outros. George P. Landow, um dos pioneiros na utilização educativa do hipertexto eletrónico, resumiu a avaliação das qualidades especificamente hipertextuais no seguinte conjunto de regras:

(1) Individual lexias should have an adequate number of links, (2) Following links should provide a satisfying experience, (3) The pleasure of following links comes from a perception of coherence, (4) such coherence can take the form of analogy, (5) Individual lexias should satisfy readers and yet prompt them to want to follow additional links, (6) The document should exemplify true hypertextuality by providing multiple lines of organization, and (7) hyper-document should fully engage the hypertextual capacities of the particular software environment employed. (Landow 2004)

Aquele conjunto de perguntas e estas regras ajudam a contextualizar as páginas web pesquisadas e a compreender melhor a sua intencionalidade, a sua história e a sua retórica. Uma análise prévia dos sítios web que podem vir a ser usados como materiais da aula ou de apoio à aula é pois uma das novas tarefas de todos os docentes de todos os níveis de ensino na era da Internet. A esta análise prévia, acrescem as fontes e recursos que possam vir a ser descobertos e sugeridos pelos próprios alunos - uma seleção decorrente dos efeitos descentralizadores e desierarquizadores dos modos de distribuição da informação em meio eletrónico. A possibilidade de encontrar materiais ricos e diversos, beneficiando do trabalho e da colaboração de outros autores e de outros leitores, é um dos factos cruciais na dinâmica documental da Internet enquanto recurso pedagógico e científico. Esta dinâmica abre um novo espaço de criatividade e de imaginação para o docente.

Um outro conjunto de regras básicas permite fazer um uso produtivo dos recursos em linha e evitar a desorientação cognitiva provocada quer 
pelo excesso de informação, quer por um nível de complexidade inadequado ao nível cognitivo e escolar do leitor. Estas regras pressupõem que o docente conheça bem os materiais que recomenda e compreenda as implicações das atividades de pesquisa sugeridas.

(1) O docente deve circunscrever claramente o objetivo da pesquisa e calcular bem o tempo requerido pelas atividades sugeridas de forma a não sobrecarregar o tempo das crianças e adolescentes dedicado a atividades escolares;

(2) não deve solicitar pesquisas automáticas inteiramente livres, muito especialmente em níveis de escolaridade mais baixos;

(3) o docente deve pré-selecionar as fontes e recomendar um número limitado de boas fontes para cada tema do programa, adequadas ao nível de conhecimento e aos objetivos propostos. Este conjunto de fontes deve ser bem conhecido pelo docente na sua estrutura hipertextual, nos seus conteúdos e nas suas ferramentas de pesquisa;

(4) quando necessário, o docente deve indicar fontes didatizadas e modularizadas (bases de dados orientadas para o ensino, incluindo coleções de exercícios; obras de consulta e de referência, como dicionários, tesauros, enciclopédias, gramáticas, etc.) ou fontes cujo potencial educativo pode ser explorado dentro ou fora da aula (por exemplo, coleções virtuais de museus; coleções indexadas de imagens ou vídeos; o arquivo em linha de uma publicação periódica; etc. cf. Anexo);

(5) os alunos devem ser levados a contextualizar as páginas encontradas, indicando o URL, o sítio web de que faz parte, eventuais autores, instituição que publica ou aloja a página, data de publicação e de consulta e outros elementos que lhes permitam tomar consciência da identidade particular da fonte consultada. Este aspeto é sistematicamente descurado nas pesquisas em linha, contribuindo para a indistinção entre texto próprio e texto alheio que carateriza muitos trabalhos escolares pós-WWW;

(6) para leituras e exercícios complementares, deve indicar projetos relevantes e credíveis dentro do campo disciplinar, adequados ao 
nível cognitivo do aprendente, ou avaliar outros sítios e páginas sugeridos pelos discentes.

Chamo a atenção para a sobreutilização de projeções, frequente no atual contexto de transformação da sala de aula em sala multimédia, com ligação permanente à Internet e ao projetor. O predomínio da visualização e da apresentação como instrumentos da retórica do ensino e da comunicação na sociedade digital corre o risco de recolocar o aprendente na situação de espetador. Este facto, não só prejudica a dimensão desejavelmente dialógica das práticas pedagógicas, como tem, por vezes, o efeito perverso de fazer passar por interativas e descentralizadas práticas que são afinal fortemente dirigidas e de natureza meramente transmissiva. O abuso da projeção de diapositivos 'powerpoint' como tecnologia didática autoevidente e autojustificada é um exemplo da recuperação das convenções expositivas no contexto da sala multimédia. De forma idêntica, a facilidade em encontrar informação através do recurso quase universal ao Google e a motores similares favorece a perceção da informação e dos documentos como objetos sem história, suscetíveis de serem gerados automaticamente no ecrã de cada utilizador. As atividades concebidas pelo docente, dentro e fora da aula, devem promover a interação com a informação e uma consciência crítica da natureza específica de cada página web, na sua estrutura e no seu conteúdo. A naturalização do hipertexto eletrónico, acentuada pela ubiquidade dos seus usos quotidianos atuais e pelo desconhecimento das operações computacionais que são tornadas invisíveis pelas interfaces gráficas, tornam particularmente difícil uma tomada de consciência crítica em contexto escolar.

$\mathrm{O}$ aumento de incidência do plágio através de trabalhos impressos a partir de fontes eletrónicas é um indicador de que a pedagogia relativa ao uso de fontes continua a não ser feita de modo sistemático no ensino secundário e no ensino superior. Os docentes devem desenvolver, de modo sistemático, uma noção de integridade na utilização de todas as fontes, bibliográficas e eletrónicas. Para isso, devem incentivar os alunos a seguir as seguintes recomendações: (1) identificar todas as fontes (autor; título; data de publicação; URL do documento; data de consulta); (2) distinguir 
sistematicamente entre citação e paráfrase no uso de fontes eletrónicas, através do recurso às aspas ou de outros marcadores de discurso citado - qualquer texto ou fragmento de texto alheio usado deve ser indicado entre aspas, mesmo em trabalhos simples de pesquisa de informação; (3) promover o reconhecimento da propriedade intelectual dos autores dos documentos, identificando-os de forma rigorosa e atribuindo-lhes as informações e ideias usadas.

Outro fator a ter conta, numa sociedade em que a distribuição da riqueza continua a ser desigual, é a possibilidade de o acesso a um computador e à Internet fora da escola não ser necessariamente universal. Para que a escola não reforce as desigualdades sociais no acesso às novas tecnologias, o docente deve garantir, para todas as atividades de pesquisa, consulta e redação que impliquem uso de computador e rede de telecomunicações, que o acesso possa ser feito também através da rede de computadores da escola e que haja condições efetivas, de espaço e de tempo, para isso acontecer - na sala de estudo, na biblioteca ou em colaboração com outras disciplinas, como Tecnologias de Informação e Comunicação. Deve ainda prever fontes de pesquisa bibliográfica alternativas ou adicionais à pesquisa eletrónica. $\mathrm{O}$ conhecimento dos livros e das fontes impressas - das suas formas de organização e indexação deve manter-se como máquina fundamental de conhecimento.

As escolas e universidades, nas suas formas atuais, não têm ainda capacidade para assimilar plenamente a Internet e o hipertexto eletrónico como modelos de ensino e aprendizagem. A persistência de um modelo estritamente disciplinar e institucional de produção e transmissão de conhecimentos baseia-se na restrição do acesso e na coincidência entre as fronteiras físicas e as fronteiras concetuais de um determinado corpus de informação. A partir do momento em que a informação se dispõe de forma reticular e desinstitucionalizada, promovendo imprevistas associações entre documentos e múltiplas trocas entre os agentes dos processos formais de aprendizagem, é possível imaginar outros modelos ou, pelo menos, uma modificação significativa dos modelos atuais. Para isso, é necessário compreendermos melhor a literacia digital enquanto conjunto de capacidades semióticas e hermenêuticas transformadas pelos modos 
de interatividade caraterísticos da cultura algorítmica. Trata-se, em suma, de compreender o potencial cognitivo das literacias digitais e descobrir como usar a dinâmica reticular da cultura eletrónica para reimaginar os processos de ensino e de aprendizagem.

\section{Considerações finais}

A enorme quantidade e diversidade de boas fontes eletrónicas torna impossível fazer uma lista dos melhores sítios com relevância para processos formais de ensino e aprendizagem, a não ser a título exemplificativo. Além disso, o desenvolvimento quase diário de novas aplicações informáticas implica a rápida desatualização e a necessidade de substituição de ferramentas que, durante algum tempo, nos pareceram imprescindíveis e se tornaram familiares. Este é talvez o aspeto mais exigente da cultura digital atual, no conteúdo informativo e nos programas informáticos: a necessidade de um esforço permanente de atualização para percebermos que recursos existem, que redes de relações reconfiguram os materiais digitais e que novas tarefas automáticas modificam a nossa interação com esses materiais. Não é demais sublinhar a importância de um conhecimento atualizado das ferramentas informáticas que nos permitem interagir melhor com o universo em constante expansão e reorganização dos recursos digitais. Usadas na edição, na publicação, na comunicação, na indexação, na tradução, na partilha de ficheiros ou na colaboração em linha, muitas dessas ferramentas são de acesso livre e de fácil utilização.

Nos anexos finais, são exemplificados dois tipos de recursos: recursos eletrónicos de pesquisa, indexação e anotação de fontes em linha que o docente pode usar como ferramentas de trabalho (Anexo A); e várias categorias de sítios web úteis no ensino da Língua Inglesa e das culturas e literaturas de Língua Inglesa (Anexo B). Há um conjunto de aplicações informáticas de instalação fácil e uso livre que podem ajudar o docente a pesquisar e a construir o seu próprio portefólio de materiais em linha. Estas ferramentas permitem pesquisar, compilar, estruturar e anotar as páginas web selecionadas, tornando mais fácil a sua indexação para 
localização e transferência futura, assim como a criação de ligações entre diferentes materiais através de classificações indexadoras definidas pelo utilizador. Estes materiais podem depois ser didatizados de acordo com temas e objetivos específicos do programa da disciplina ou usados para atividades exploratórias. Há também diversas ferramentas de edição e de publicação que podem ser úteis para projetos escolares de natureza colaborativa.

No Anexo B, são indicados alguns sítios web em acesso livre úteis para o docente de Inglês. Muitas das editoras de manuais escolares dispõem dos seus centros de recursos e dos seus materiais didatizados em linha. Existem também organismos que certificam o software educativo, avaliando a sua pertinência para uso em contexto escolar. É o caso, em Portugal, do Sistema de Avaliação, Certificação e Apoio à Utilização de Software para a Educação e a Formação (SACAUSEF), da Equipa de Recursos e Tecnologia Educativas, que integra o Plano Tecnológico Nacional. ${ }^{7}$ Uma das grandes vantagens da Internet no domínio do ensino das línguas, literaturas e culturas reside no facto de ter tornado acessíveis inúmeras fontes históricas e contemporâneas nas línguas originais, enriquecendo o corpus de materiais de que o docente de língua estrangeira ou de língua segunda pode dispor nas suas atividades. Dois exemplos óbvios são o acesso a ficheiros de texto, de imagem, de som e de vídeo da imprensa, da rádio e da televisão, e o acesso a materiais institucionais de arquivo, como acontece com as bibliotecas e os museus.

Com a digitalização maciça do património cultural e artístico e com a gradual universalização do acesso à Internet nas salas de aula em todos os

7 Nos cinco cadernos produzidos entre 2005 e 2009 pelo SACAUSEF é evidente a preponderância de um modelo educativo restritivo na concetualização do valor educativo dos recursos digitais. Mas a didatização digital de conteúdos curriculares específicos ou a adaptação de ferramentas digitais a processos curriculares são apenas dois aspetos da mudança tecnocultural em curso. Cf. Cadernos SACAUSEF I: Utilização e Avaliação de Software Educativo http://www.crie.min-edu.pt/index.php?section=176; Cadernos SACAUSEF II: Avaliação de Locais Virtuais de Conteúdo Educativo http://www.crie.min-edu.pt/index. php?section=224; Cadernos SACAUSEF III: A dimensão do Género nos Produtos Educativos Multimédia http://www.crie.min-edu.pt/index.php?section=229; Cadernos SACAUSEF IV: Software Livre na Educação http://www.crie.min-edu.pt/index.php?section=233; e Cadernos SACAUSEF V: Recursos Educativos Digitais de Qualidade ao Serviço das Escolas http://www. crie.min-edu.pt/index.php?section=314 (consultado a 26 Ago 2010). 
níveis de ensino, os objetos dos novos média passam a ocupar um lugar central no currículo, seja ao nível metodológico, seja ao nível do conteúdo. Isto implica o desenvolvimento, não tanto de uma literacia multimédia na qual a maior parte dos alunos atuais são muito fluentes -, mas sim de um conjunto de novas aptidões de análise crítica da imagem, da imagem em movimento e da cultura digital em geral, capazes de atingir o nível de sofisticação da análise linguística e literária tradicional. Embora a socialização nas imagens, nas imagens em movimento e nos códigos gráficos dos ambientes hipermédia tenda a tornar-se comum na sociedade da informação - até para as gerações mais velhas -, continua a ser incipiente o ensino das metalinguagens de análise formal e retórica desses códigos. É importante que o uso destas fontes não se limite ao seu conteúdo linguístico ou informativo, mas procure chamar a atenção para a pragmática das formas de comunicação gráfica, visual e cinematográfica. A educação para os média é essencial para que os indivíduos aprendam a conhecer e a criticar a sua retórica específica. A utilização produtiva do hipertexto eletrónico na aprendizagem e no ensino implica, em última análise, o desenvolvimento dessa capacidade de leitura crítica do próprio meio.

\section{Referências ${ }^{8}$}

\subsection{Bibliografia}

Crystal, D. 2006. Language and the Internet. Cambridge: Cambridge University Press.

Dearnley, J. e J. Feather. 2001. The Wired World: An Introduction to the Theory and Practice of the Information Society. London: Library Association Publishing.

\footnotetext{
${ }^{8}$ Das obras citadas na bibliografia, recomendo a leitura do livro de David Crystal, uma obra essencial para todos os professores de língua. Language and the Internet oferece uma visão panorâmica da interferência da Internet nos processos de comunicação e nos códigos linguísticos, fazendo ao mesmo tempo uma introdução ao funcionamento da Internet e à comunicação mediada por computador. A obra de James Dearnley e John Feather (2001) constitui também uma introdução acessível aos protocolos de comunicação em rede na sociedade de informação. O artigo de N. Katherine Hayles (2010) analisa as dinâmicas de leitura criadas pelas literacias digitais.
} 
Dudeney, G. 2007. The Internet and the Language Classroom. Cambridge: Cambridge University Press $\left[1 .^{a}\right.$ ed. 2000].

HaYles, N. K. 2008. Electronic Literature: New Horizons for the Literary. Notre Dame, Indiana: University of Notre Dame.

Hayles, N. K. 2010. How We Read: Close, Hyper, Machine. ADE Bulletin, N. ${ }^{\circ}$ 150, $62-79$.

LANDOw, G. P. 2006. Hypertext 3.0: Critical Theory and New Media in an Era of Globalization, Baltimore: Johns Hopkins UP.

MANOVICH, L. 2010. How to read 1,000,000 Manga pages? Visualizing patterns in literature, print culture, visual art, cinema, animation, and games. Conferência proferida na Faculdade de Letras da Universidade de Coimbra, 18 de Junho.

Nelson, T. H. 2003. A File Structure for the Complex, the Changing, and the Indeterminate [1965]. In Wardrip-Fruin, N. e N. Montfort. (Eds.). The New Media Reader. Cambridge, Mass.: MIT Press, 133-145.

McGann, J., A. Stauffer, D. Wheeles e M. Pickard. (Eds.). 2010. Online Humanities Scholarship: The Shape of Things to Come. Houston, Texas: Rice University Press. Turkle, S. 1989. O Segundo Eu: Os Computadores e o Espírito Humano. Trad. Manuela Madureira. Lisboa: Editorial Presença.

Turkle, S. 1997. A Vida no Ecrã: A Identidade na Era da Internet. Trad. Paulo Faria. Lisboa: Relógio de Água.

\subsection{Webgrafia}

Davidson, C. N. e D. T. GoldBerg. 2009. The Future of Learning Institutions in a Digital Age. Cambridge, Mass: MIT Press. Disponível em linha: http://mitpress. mit.edu/books/full_pdfs/Future_of_Learning.pdf (consultado a 26 Ago 2010)

Davidson, C. N. e D. T. GoldBerg. 2010. The Future of Thinking: Learning Institutions in a Digital Age, Cambridge, Mass: MIT Press. Disponível em linha: http://mitpress.mit.edu/books/full_pdfs/Future_of_Thinking.pdf (consultado a 26 Ago 2010)

Hendler, J., N. Shadbolt, W. Hall, T. Berners-lee e D. Weitzner. 2008. Web Science: An Interdisciplinary Approach to Understanding the Web. In Communications of the ACM, Volume 51, Issue 7 (July 2008): 60-69. Disponivel 
em linha em http://portal.acm.org/citation.cfm?id=1364798 (consultado a 26 Ago 2010)

LANDOW, G. P. 2004. Is this hypertext any good? Evaluating quality in hypermedia. In dichtung-digital: journal für digitale ästhetik 2004/3, http://www.brown. edu/Research/dichtung-digital/2004/3/Landow/index.htm (consultado a 26 Ago 2010) 
- zotero

http://www.zotero.org/

Esta ferramenta, desenvolvida pelo Centro de História e Novos Média da Universidade George Mason nos E.U.A., funciona associada ao programa de navegação de páginas web (está disponível para os sistemas operativos Mac, Windows e Linux). As funcionalidades do zotero permitem guardar páginas web de forma mais flexível do que a mera marcação dos favoritos permitida pelo browser, possibilitando arquivar de forma estruturada, indexada e anotada as páginas selecionadas. Possibilita também a partilha colaborativa dos arquivos construídos com outros utilizadores do programa.

\section{- WordPress}

http://wordpress.com/

Uma das diversas aplicações usadas na criação de blogues. Possui um conjunto de modelos pré-formatados, no seu grafismo e nas suas funcionalidades, o que torna relativamente simples a edição e publicação de textos, imagens e vídeos. A assinatura do serviço permite uma intervenção na folha de estilos com o código html dos modelos pré-definidos, introduzindo um certo grau de personalização da apresentação e das funcionalidades. Entre os serviços similares, refiram-se: Blogger http://www.blogger.com/; LiveJournal http://www.livejournal. com/; blog drive http://www.blogdrive.com/; bravenet http://www. bravenet.com/. No que se refere à criação de Wikis e de sítios web, existem múltiplas aplicações e espaços de trabalho de acesso livre em linha. Refiram-se, a título de exemplo, PBWorks http://pbworks.com/ e Wix http://www.wix.com/

\section{- Box.net}

https://www.box.com/

Serviço de armazenamento, partilha e edição de ficheiros e de colaboração em linha. Entre os serviços similares, refiram-se DropBox https:// 
www.dropbox.com, Google Docs http://docs.google.com/ e Acrobat. com https://www.acrobat.com

- The Open Video Project http://www.open-video.org/index.php Projeto do Laboratório de Design Interactivo da Faculdade de Informação e Ciências Documentais da Universidade da Carolina do Norte, em Chapel Hill, cujo objetivo é tornar pesquisável de forma integrada múltiplos repositórios de ficheiros vídeo, incluindo documentários e vídeos educativos.

\section{- i-Tunes U}

http://www.apple.com/education/itunes-u/

Plataforma da Apple que integra um conjunto de aplicações de construção de cursos, manuais e recursos didáticos com um arquivo de aulas e de vídeos de natureza educativa. 


\section{ANEXO B}

1. Dicionários e tesauros

- Cambridge Online Dictionaries (Cambridge Advanced Learner's Dictionary; Cambridge Dictionary of American English; Cambridge International Dictionary of Idioms; Cambridge International Dictionary of Phrasal Verbs) http://dictionary.cambridge.org/

- The Merriam-Webster Collegiate Dictionary and Thesaurus online http://www.merriam-webster.com/

- OneLook Dictionary Search http://www.onelook.com/(Motor de pesquisa que agrega múltiplos dicionários no mesmo universo de pesquisa.)

- Dictionary.com http://dictionary.reference.com/

- Thesaurus.com http://www.thesaurus.com/

2. Gramáticas e bases de dados de exercícios em linha

- The Internet Grammar of English http://www.ucl.ac.uk/internet-grammar/

- The Glossary of English Grammar Terms http://www.usingenglish.com/glossary.html

- UsingEnglish.Com [Resources for English as a Second Language] http://www.usingenglish.com/

- Onestopenglish [MacMillan] http://www.onestopenglish.com/

- ESLgold.net www.eslgold.com/

3. Imprensa periódica, canais de rádio e televisão na Internet

- The Guardian http://www.guardian.co.uk/(O motor de pesquisa permite aceder a uma parte significativa de todo o arquivo do jornal.) 
- PBS Public Broadcasting Service http://www.pbs.org/(Possui em arquivo vídeos com reportagens emitidas. Destaco o programa 'Frontline'.)

- Aljazeera http://english.aljazeera.net/ (Possui em arquivo vídeos com reportagens emitidas, geralmente abordando problemas numa perspectiva multicultural e multi-regional, que ajuda a compreender as dinâmicas do mundo globalizado. Destaco os programas 'Witness', 'Fault Lines', 'Inside Story' e 'People \& Power'.)

- BBC Radio 4 http://www.bbc.co.uk/radio4/ (Para além dos ficheiros com alguns programas da semana, possui em arquivo um conjunto selecionado de podcasts.)

4. Bases de dados de história social, cultural e política

- BBC British History in-depth http://www.bbc.co.uk/history/british/

- Timelines: Sources from History http://www.bl.uk/learning/timeline/index.html

- British History Online http://www.british-history.ac.uk/

- SchoolHistory.co.uk http://www.schoolhistory.co.uk/

- History Matters: The U.S. Survey Course on the Web http://historymatters.gmu.edu/

5. Museus

- National Gallery [Londres] http://www.nationalgalleryimages.co.uk/

- National Gallery of Art [Washington, D.C.] http://www.nga.gov/

- The Metropolitan Museum of Art http://www.metmuseum.org/ 
- MOMA - Museum of Modern Art

http://www.moma.org/

- Tate Modern

http://www.tate.org.uk/

6. Bases de dados e bibliotecas virtuais de materiais

- Europeana

http://www.europeana.eu/portal/(Base de dados que integra mais de 6 milhões de itens do património cultural europeu, sob a forma de ficheiros de imagem, texto, som e vídeo. Os itens digitalizados fazem parte das coleções de museus, galerias, bibliotecas, mediatecas e arquivos.)

- World Digital Library

http://www.wdl.org/en/(Apresentada em 2009, a Biblioteca Digital Mundial tem como objetivo dar a conhecer o património cultural dos países membros da UNESCO, dando ênfase à representação digital de materiais primários (manuscritos, mapas, livros raros, registos sonoros, filmes, gravuras, fotografias, plantas arquitetónicas, etc.)

- Europa Film Treasures

http://www.europafilmtreasures.eu/(Projeto destinado a preservar e a dar a conhecer em formato digital as primeiras décadas da imagem em movimento através de filmes recuperados dos arquivos de diversas instituições europeias.)

- Learning at the British Library

http://www.bl.uk/learning/index.html (Secção do sítio web da Biblioteca Britânica que indexa projetos educativos baseados na exploração dos tesouros e obras das suas coleções.)

- Computer History Museum

http://www.computerhistory.org/ (O Museu de História do Computador, sedeado em Mountain View, na Califórnia, tem em linha materiais produzidos para diversas exposições, entre as quais uma história da Internet, produzida em 2006 ['Internet History, 1962-1992', http:// www.computerhistory.org/internet_history/].) 